УДК 378.637

DOI 10.37386/2413-4481-2021-2-59-64

Т.В. Дмитроченко

Амурский гуманитарно-педагогический государственный университет, г. Комсомольск-на-Амуре, Россия

ИСПОЛЬЗОВАНИЕ ФОРМИРУЮЩЕГО ЭКСПЕРИМЕНТА
В РАЗВИТИИ КРИТИЧЕСКОГО МЫШЛЕНИЯ
И СТАНОВЛЕНИИ СУБЪЕКТНОСТИ БУДУЩИХ ПЕДАГОГОВ

Статья посвящена актуальной проблеме развития критического мышления и становления субъектности будущего педагога в условиях современного мира. Представлен теоретический анализ литературы по рассмотренной проблеме, на основании осуществленного анализа автором статьи приведены уточненные определения понятий «субъектность» и «критическое мышление». Описаны ход и результаты формирующей работы по развитию критического мышления и становления субъектности будущих педагогов. В статье приведено обоснование разработанного диагностического комплекса методик, необходимого для проведения исследования, а также комплекса внешних и внутренних психологопедагогических условий. Представлены результаты исследования, подтверждающие эффективность реализованного комплекса условий и динамику формирования исследуемых качеств личности будущего педагога.

Ключевые слова: критическое мышление, субъектность, профессиональная субъектность будущего педагога, уровень субъектности, уровень развития критического мышления, комплекс методик, будущий педагог.

T.V. Dmitrochenko

Amur State University of Humanities and Pedagogy, Komsomolsk-on-Amur, Russia

\title{
THE USE OF A FORMATIVE EXPERIMENT IN THE DEVELOPMENT OF CRITICAL THINKING AND FORMATION OF THE SUBJECTIVITY OF FUTURE TEACHERS
}

\begin{abstract}
The article is devoted to the urgent problem of the development of critical thinking and the formation of the subjectivity of a future teacher in the modern world. A theoretical analysis of literature on the problem considered is presented. On the basis of the analysis the author of the article specified definitions of the concepts "subjectivity" and "critical thinking". The course and results of experimental work on the development of critical thinking and the formation of subjectivity of future teachers are presented. The article provides the rationale for the developed diagnostic complex of methods necessary for the study, as well as a complex of external and internal psychological and pedagogical conditions. The results of the study are presented that confirm the effectiveness of the implemented set of conditions and the dynamics of the formation of the studied personality traits of the future teacher.

Key words: critical thinking, subjectivity, professional subjectivity of a future teacher, level of subjectivity, level of development of critical thinking, methodological complex, future teacher.
\end{abstract}

В условиях модернизации современного мира, увеличения объема знаний и количества информации, цифровизации различных сфер современного общества возрастают требования к личности и профессиональной компетентности современного педагога. Согласно нормативноправовым документам РФ (Концепция развития непрерывного образования взрослых в Российской Федерации на период до 2025 года, Национальный проект «Образование», Федеральный государственный образовательный стандарт выс- шего образования (ФГОС ВО 3++) и др.) обществу в наши дни необходим педагог, обладающий развитыми навыками критического мышления, способный осуществлять личностное и профессиональное развитие на протяжении всей жизни.

Современный педагог стоит перед необходимостью осмысления данных требований к своей личности и профессиональной подготовке в условиях современной образовательной парадигмы. Данные требования достаточно высоки. Обществу необходим не просто педагог, обладающий 
сформированными группами компетенций, перечисленных в стандарте направления подготовки, но и профессионал, обладающий на достаточном уровне развитыми навыками критического мышления, позволяющими ему качественно работать с различными видами профессиональной информации, использовать профессиональные знания для личностного и профессионального развития в условиях непрерывного профессионального образования.

О формировании критического мышления и субъектных качеств личности будущего педагога, являющихся условием непрерывного роста его образовательного потенциала, отмечено в законе РФ «Об образовании», Концепции развития непрерывного образования взрослых в Российской Федерации на период до 2025 года, Национальном проекте «Образование», Федеральном государственном образовательном стандарте высшего образования (ФГОС ВО 3++) и других нормативно-правовых документах РФ. Вопросы становления субъектности педагога, развития его критического мышления рассмотрены в трудах зарубежных и отечественных исследователей.

Так, например, ученый-психолог А.С. Байрамов рассматривает критическое мышление как способность личности не воспринимать полностью на веру утверждения, проверять истинность высказываний, способность вырабатывать свой критический взгляд и критическое отношение к событиям и явлениям действительности [1, с. 34]. Известный педагог М.В. Кларин имеет аналогичную точку зрения. В его работах критическое мышление связано с характеристиками рациональности, целенаправленности, организованности, рефлексивности [1, с. 41].

Исследователь Ю.А. Кукушкина определяет критическое мышление как взаимосвязанный комплекс когнитивных и матакогнитивных стратегий и навыков решения жизненных и профессиональных задач. Ученый рассматривает феномен критического мышления в контексте профессиональной подготовки будущего специалиста и отмечает, что данный навык является условием успешности решения профессиональных задач [2, c. 75].

Как рефлексивный процесс «осознания своего мышления» рассмотрен исследуемый нами феномен и в работах Т.А. Ольховой. Исследователь не сводит критическое мышление только к совокупности интеллектуальных умений и навыков, а рассматривает его в качестве основы для развития информационно-познавательной активности личности, признавая при этом важность готовно- сти личности к использованию этих непредметных навыков не только в учебной деятельности, но в реальных жизненных ситуациях [3, с. 48].

Е.С. Заир-Бек рассматривает критическое мышление как качество личности, взаимосвязанное со смысловым самоопределением личности [4, с. 82]. И.А. Мороченкова и Н.Ю. Туласынова связывают критическое мышление с процессами самопознания, самообразования и самореализации. О взаимосвязи критического мышления с субъектностью отмечено в работах Т.А. Ольховой и Т.С. Хабаровой [3, с. 86].

В зарубежных исследованиях (Д. Клустер, Б. Рассел, Д. Халпен, Дж. Чеффи) под критическим мышлением понимается рефлексивное, оценочное мышление, направленное на проверку истинности получаемой информации и зависящее от эффективности использования навыков критического мышления. Круг навыков критического мышления в зарубежной и отечественной науке на сегодняшний день точно не определен. В рамках рассматриваемых концепций можно сделать вывод, что к навыкам критического мышления ученые относят прогнозирование, оценку, анализ, синтез, сравнение, рефлексию и др.

Анализ представленных психолого-педагогических исследований позволил определить, что в настоящий момент в зарубежной и отечественной литературе недостаточно широко разработана проблема развития критического мышления и становления субъектности будущих педагогов в процессе профессиональной подготовки.

В рамках данного исследования под критическим мышлением понимается рефлексивное мышление будущего педагога, позволяющее ему эффективно работать с различными видами профессиональной информации (сравнивать, анализировать, оценивать), отличать факты от допущений, приводить аргументацию в защиту своего мнения, решать типовые и нестандартные профессиональные задачи.

Критическое мышление можно рассматривать в качестве средства становления субъектности студента педагогического вуза, позволяющего ему не только эффективно работать с информацией, но и осмысливать собственные личностные и профессиональные достоинства и недостатки, выстраивать вектор своего развития, саморазвиваться и самореализовываться в условиях непрерывного профессионального образования.

Феномен субъектности личности рассмотрен в работах ученых К.А. Абульхановой-Славской, Б.Г Ананьева, Л.И. Анциферовой, Т.В. Белых, А.В. Брушлинского, Е.Ю. Коржовой, Д.А. Леон- 
тьева, Б.Ф. Ломова, С.Л. Рубинштейна, В.Э. Чудновского, М.А. Щукиной. Под субъектностью данные ученые понимают одну их ключевых характеристик личности, позволяющую ей быть активным субъектом и творцом собственной жизни, осознанно и ответственно относиться к своей деятельности, осуществлять рефлексию и саморазвитие на протяжении всей жизни [5, с. 45].

Вопросы профессиональной субъектности студента рассмотрены в работах Н.М. Борытко, А.А. Деркач, Ф.Г. Мухаметзяновой, В.А. Сластенина. В работах данных исследователей профессиональная субъектность будущего специалиста представлена многоплановой характеристикой его личности, отмечающейся активным творческим отношением к получаемой профессии, успешной адаптацией в непрерывно меняющейся социокультурной ситуации, проявлением самостоятельности и активности в профессиональнообразовательном пространстве вуза, осуществлением продуктивного педагогического взаимодействия с субъектами образовательного процесса, с осознанием ответственности за результаты получаемого образования [6, с. 86].

В рамках настоящего исследования под профессиональной субъектностью будущего педагога понимается интегративное качество его личности, определяющееся достаточным уровнем рефлексии, самопознания, субъектного опыта, позволяющих студенту как будущему субъекту педагогической деятельности осуществлять непрерывное саморазвитие и самореализацию в условиях непрерывного профессионального образования.

Формирующая работа по развитию критического мышления и становлению субъектности студентов-педагогов включала в себя констатирующий, формирующий и контрольный этапы.

На констатирующем этапе педагогического эксперимента мы изучили уровни субъектности и развития критического мышления у испытуемых контрольной и экспериментальной групп, вопервых, с целью установления первоначального уровня развития исследуемых в данной работе качеств личности будущего специалиста. Во-вторых, для установления прямой корреляционной зависимости между уровнем развития критического мышления и субъектностью студентов-педагогов. B-третьих, для проверки предположения о том, что субъектность и критическое мышление будущих педагогов не будут формироваться без создания специальных психолого-педагогических условий и являются сложными интегральными качествами, развивающимися на протяжении всей жизни и обеспечивающими специалисту возможность его профессионального развития.

Объектом нашего исследования является профессионально-образовательный процесс педагогического вуза. Предмет исследования - уровень субъектности и развития критического мышления студентов-педагогов, обучающихся в ФГБОУ ВО «Амурский гуманитарно-педагогический государственный университет».

Гипотезой данного исследования является предположение, что становлению субъектности и развитию критического мышления будущих педагогов будет способствовать специально разработанный комплекс внешних и внутренних психолого-педагогических условий. Целью исследования явилась апробация и проверка эффективности комплекса выдвинутых внутренних и внешних психолого-педагогических условий развития критического мышления и становления субъектности будущих педагогов.

В своей работе мы применили следующие методы исследования: теоретические (анализ, синтез, обобщение научной литературы), эмпирические (тестирование, рейтинг, метод экспертных оценок), методы математической статистики (коэффициент корреляции Спирмена, многофункциональный критерий Фишера).

Экспериментальную группу исследования (далее - ЭГ) составили 20 человек (студенты 2-го курса направления подготовки 44.03.05 «Педагогическое образование (с двумя профилями подготовки)», профили «Русский язык» и «Литература»). Контрольную группу исследования (далее КГ) составили 22 человека (студенты 2-го курса направления подготовки 44.03.05 «Педагогическое образование (с двумя профилями подготовки)», профили «Начальное образование» и «Иностранный язык»).

Представленную выборку составили студенты, имеющие средний и высокий уровень успеваемости, достаточно устойчивые мотивы учебнопрофессиональной педагогической деятельности, желающие связать свою будущую профессиональную деятельность с работой в образовательных организациях. Необходимо отметить, что с представленными группами студентов на ранних этапах обучения не проводилась целенаправленная формирующая работа по развитию критического мышления и становлению субъектности.

При помощи разработанного комплекса диагностических методик нами был определен уровень субъектности и развития критического мышления студентов. Уровень субъектности личности будущего педагога был нами выявлен 
по сумме следующих показателей: самопознание, рефлексия и субъектный опыт личности, самореализация. Для оценки уровня самопознания мы использовали «Методику исследования самоотношения» (С.Р. Пантилеев) [7, с. 18]. Уровень рефлексии и субъектного опыта был нами оценен по «Опроснику рефлексивности» (А.В. Карпов) [8, с. 50]. Для оценки третьего показателя - самореализации - мы использовали «Многомерный опросник самореализации личности» (С.И. Кудинов) [9, с. 54]. По каждой отдельной методике мы выявили уровень показателей субъектности личности (достаточный, средний, низкий). Путем суммирования показателей нами был определен общий уровень субъектности каждого студента как интегрального качества его личности.

Для определения уровня развития критического мышления студентов-педагогов нами была разработана методика, направленная на оценку умений критической работы обучающихся с учебно-профессиональной информацией. Данная методика была нами взята из Международной программы по оценке образовательных достижений учащихся (PISA), доработана и апробирована применительно к процессу профессиональной подготовки будущего педагога. Представленные в тексте методики задания позволят оценить навыки анализа информации, синтеза, дедукции, индукции, умения проверять истинность различных высказываний, разграничивать факты и допущения, устанавливать причинно-следственные связи между явлениями, решать нестандартные жизненные и профессионально-педагогические задачи в ситуации неопределенности.

На констатирующем этапе педагогического эксперимента в ЭГ достаточный уровень субъектности был выявлен у 25 \% участников исследования, средний уровень - у 50 \% испытуемых, низкий - у 25 \% студентов. У 20 \% испытуемых ЭГ был выявлен достаточный уровень развития критического мышления, у 55 \% студентов - средний уровень, у $25 \%$ - низкий уровень.

В КГ достаточный уровень субъектности был выявлен у 18 \% участников исследования, средний уровень - у 55 \% испытуемых, низкий - у $27 \%$ студентов. У 14 \% испытуемых КГ был выявлен достаточный уровень развития критического мышления, у 64 \% студентов - средний уровень, у $22 \%$ - низкий уровень.

Деятельность студентов, демонстрирующих достаточный уровень развития критического мышления и субъектности, характеризовалась достаточным уровнем развития представленных в комплексе методик показателей (самопознание, актуализированный субъектный опыт и рефлексия, самореализация). Для испытуемых со средним уровнем развития критического мышления и субъектности был характерен средний уровень представленных показателей. Для деятельности студентов с низким уровнем исследуемых качеств, соответственно, был характерен низкий уровень обозначенных показателей.

Определение достоверности различий между полученными в ходе педагогического исследования процентными долями двух выборок ЭГ и КГ осуществлялась с помощью многофункционального критерия Фишера ( $\varphi^{\star}$-критерий). Так как полученное $\varphi^{\star}$ эмп. $=0,553$ меньше $\varphi^{\star}$ критич. $=1,64$, то это означает, что на уровне значимости $\mathrm{p}>0,05$ процентные доли будущих педагогов ЭГ и КГ с достаточным и средним уровнями развития критического мышления и субъектности значимо не различаются.

Так как по результатам констатирующего этапа исследования был определен недостаточный уровень сформированности исследуемых качеств будущих педагогов, нами был предложен комплекс внешних и внутренних психолого-педагогических условий развития критического мышления и становления субъектности будущих педагогов.

К внутренним условиям развития критического мышления и становления субъектности студентов-педагогов мы относим: развитие учебных и профессиональных мотивов деятельности; мобилизация и стимулирование внутреннего потенциала студентов; использование процедур рефлексии; обогащение и актуализация субъектного опыта; развитие у будущего педагога внутренней потребности к самопознанию, саморазвитию в условиях непрерывного профессионального образования.

К внешним условиям развития критического мышления и становления субъектности студентов-педагогов мы относим: создание субъектного педагогического взаимодействия; использование активных и интерактивных методов профессионального обучения, продуктивных технологий профессионального образования; учет индивидуальных, личностных, профессиональных способностей обучающихся; использование диагностических методик, позволяющих оценить уровень исследуемых качеств; использование субъектно-ориентированных, проблемно-поисковых профессиональных ситуаций в образовательном процессе вуза; формирование ответственности за результаты собственного образования.

Формирующая работа была направлена на реализацию в профессионально-образовательном 
процессе педагогического вуза описанных выше условий на учебных занятиях по дисциплине «Педагогика». Работа велась по трем направлениям:

- формирование умений работать с научными текстами (формирование умений по работе с понятиями научного текста, формирование умений работать со структурой научного текста, формирование умений представлять собственный (вторичный) научный текст);

- формирование умений решать профессионально-педагогические задачи (анализ педагогических ситуаций, решение педагогических задач, составление конспектов классных часов, родитель- ских собраний, массовых мероприятий, коллективно-творческих дел);

- развитие коммуникативной культуры студентов (умение представлять письменный текст в устной форме, слушать и слышать собеседника, выражать собственную позицию, умения и навыки публичных выступлений и др.).

На этапе контрольного эксперимента по итогам проведенной формирующей работы мы можем обнаружить динамику изменения уровня развития критического мышления и становления субъектности будущих педагогов, представленную в таблице.

Динамика изменения уровня развития критического мышления и становления субъектности будущих педагогов

\begin{tabular}{|c|c|c|c|c|c|c|c|}
\hline \multirow[b]{2}{*}{ Качества } & \multirow{2}{*}{$\begin{array}{c}\text { Этап формирующего } \\
\text { эксперимента }\end{array}$} & \multicolumn{2}{|c|}{ Достаточный уровень } & \multicolumn{2}{|c|}{ Средний уровень } & \multicolumn{2}{|c|}{ Низкий уровень } \\
\hline & & $\begin{array}{l}\text { Кол-во } \\
\text { чел. }\end{array}$ & $\%$ & $\begin{array}{c}\text { Кол-во } \\
\text { чел. }\end{array}$ & $\%$ & $\begin{array}{l}\text { Кол-во } \\
\text { чел. }\end{array}$ & $\%$ \\
\hline \multicolumn{8}{|c|}{ Экспериментальная группа (ЭГ) } \\
\hline \multirow[t]{2}{*}{ Субъектность } & $\begin{array}{l}\text { Начало формирующего } \\
\text { эксперимента }\end{array}$ & 5 & 25 & 10 & 50 & 5 & 25 \\
\hline & $\begin{array}{l}\text { Окончание формирующего } \\
\text { эксперимента }\end{array}$ & 7 & 35 & 12 & 60 & 1 & 5 \\
\hline \multirow{2}{*}{$\begin{array}{l}\text { Развитие } \\
\text { критического } \\
\text { мышления }\end{array}$} & $\begin{array}{l}\text { Начало формирующего } \\
\text { эксперимента }\end{array}$ & 4 & 20 & 11 & 55 & 5 & 25 \\
\hline & $\begin{array}{l}\text { Окончание формирующего } \\
\text { эксперимента }\end{array}$ & 6 & 30 & 13 & 65 & 1 & 5 \\
\hline \multicolumn{8}{|c|}{ Контрольная группа (КГ) } \\
\hline \multirow[t]{2}{*}{ Субъектность } & $\begin{array}{l}\text { Начало формирующего } \\
\text { эксперимента }\end{array}$ & 4 & 18 & 12 & 55 & 6 & 27 \\
\hline & $\begin{array}{l}\text { Окончание формирующего } \\
\text { эксперимента }\end{array}$ & 4 & 18 & 14 & 64 & 4 & 18 \\
\hline \multirow{2}{*}{$\begin{array}{l}\text { Развитие } \\
\text { критического } \\
\text { мышления }\end{array}$} & $\begin{array}{l}\text { Начало формирующего } \\
\text { эксперимента }\end{array}$ & 3 & 14 & 14 & 64 & 5 & 22 \\
\hline & $\begin{array}{l}\text { Окончание формирующего } \\
\text { эксперимента }\end{array}$ & 3 & 14 & 16 & 73 & 3 & 13 \\
\hline
\end{tabular}

Анализ данных, представленных в таблице, позволяет сделать вывод о более выраженной положительной динамике в развитии критического мышления и становлении субъектности студентов ЭГ. В результате анализа полученных данных можно утверждать, что в ЭГ произошло существенное уменьшение доли будущих педагогов, имеющих низкий уровень исследуемых качеств, и увеличение доли студентов, имеющих достаточный и средний уровни развития критического мышления и субъектности.

Для выявления изменений в динамике развития критического мышления и становления субъектности будущих педагогов дополнительно использовались методы экспертных оценок (пре- подавателей вуза и работодателей) и самооценки. Для оценки достоверности различий между процентными долями двух выборок ЭГ и КГ на момент окончания формирующего эксперимента был применен многофункциональный крите-

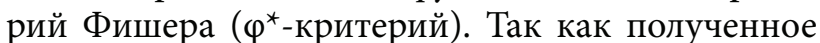
$\varphi^{*}$ эмп. $=1,885$ больше $\varphi^{*}$ критич. $=1,64$, то $\varphi^{*}$ эмп. попало в зону «значимости различий», что дает основание утверждать, что имеются значимые различия процентных долей с достаточным и средним уровнями исследуемых качеств студентов ЭГ и КГ на окончание формирующего эксперимента по сравнению с его началом.

Таким образом, проведенная формирующая работа по развитию критического мышления и 
субъектности будущих студентов была эффективна, позволила достичь целей исследования, подтвердить его гипотезу и результативность реализации разработанного комплекса внешних и внутренних психолого-педагогических условий. По результатам проведенной работы можно отметить, что увеличилось количество студентов, имеющих достаточный и средний уровень развития критического мышления и становления субъектности. Это нашло свое отражение в личностно-профессиональном росте студентов, улучшении их академической успеваемости, формировании устойчивого профессионального интереса и желании развиваться на протяжении всей жизни.

\section{Библиографический список}

1. Астахова Л. В., Харлампьева Т. В. Критическое мышление как средство обеспечения информационнопсихологической безопасности личности. М.: РАН, 2009. 136 с.

2. Кукушкина Ю. А., Спиридонов В. Ф. Критическое мышление как фактор профессиональной компетентности программистов // Психология. 2008. Т. 5, № 1. С. 72-80.

3. Ольховая Т. А. Критическое мышление как основа развития информационно-познавательной самостоятельности студентов // Высшее образование сегодня. 2013. № 9. С. 46-51.

4. Заир-Бек С. И. Развитие критического мышления на уроке: пособие для учителей общеобразовательных учреждений. М.: Просвещение, 2011. 223 с. $346 \mathrm{c}$.

5. Щукина М. А. Психология саморазвития личности. СПб.: Изд-во Санкт-Петербургского гос. ун-та, 2015.

6. Борытко Н. М. Пространство воспитания: образ бытия. Волгоград, 2000. 225 с.

7. Пантилеев С. Р. Методика исследования самоотношения. М.: Смысл, 1993. 32 с.

8. Карпов А. В. Рефлексивность как психическое свойство и методика ее диагностики // Психологический журнал. 2003. Т. 24, № 5. С. 45-57.

9. Кудинов С. И. Психодиагностика личности: учеб. пособие. Тольятти: Изд-во ТГУ, 2012. 270 с. 